\title{
Worden's Task-Based Model for Treating Persistent Complex Bereavement Disorder During the Coronavirus Disease-19 Pandemic: A Narrative Review
}

\author{
Mohsen Khosravi* \\ Department of Psychiatry and Clinical Psychology, Zahedan University of Medical Sciences, Zahedan, Iran
}

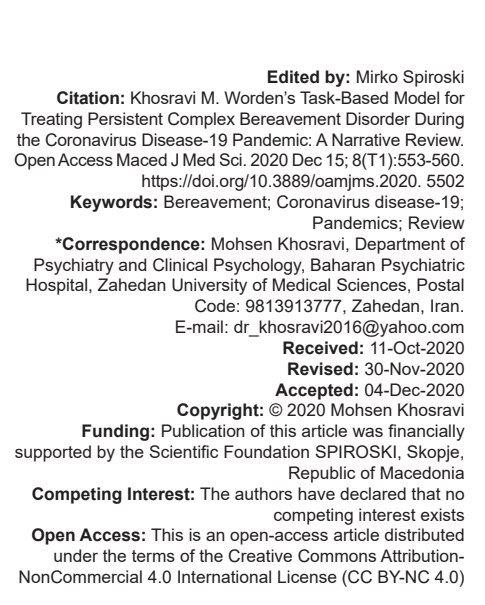

Introduction

Dying could be assumed as a developmental concomitant of living and a part of the birth-to-death continuum [1]. Life could involve a number of tragic deaths. Bereavement and grief implicate the mental reactions of the survivors of a significant loss [2]. The expression "bereavement" stands for a universal experience of losing or loss, especially after the death of a loved one. Grief means an emotional, cognitive, physical, and behavioral reaction of a person to bereavement [3]. Recent trajectory studies [4], [5], [6] have challenged the traditional "grief work" view of emotion during bereavement [7], [8]. These studies revealed that a recovery pattern could not merely characterize how to cope with loss (i.e., high chronic distress levels or initial escalated distress post-loss followed by a noticeable decrease). Actually, the most common response has been found to be a resilient pattern (i.e., low levels of stable distress) [4], [5], [6]. However, following the natural death (e.g., an illnessinduced death) of a significant other, a total of $10-20 \%$ of individuals show chronic complaints, including depression, disturbed grief reactions, and/or posttraumatic stress disorder (PTSD) [5], [6]. These disturbed grief reactions that bring about high levels of life distress and impairments are called persistent complex bereavement disorder (PCBD) in the fifth Diagnostic and Statistical Manual of Mental Disorders (DSM-5) [9] and frequently comorbid with depression and PTSD [10].

In recent months, the coronavirus disease (COVID)-2019 pandemic has disrupted the usual process of mourning by delaying the funerals and burials, the impossibility to embrace the deceased warmly, and missing the opportunity to say goodbye before death [11], [12], [13]. According to several studies, by the end of 2020, this pandemic could cause millions of deaths due to high transmission speed and current estimated case-fatality rates (3:4) all around the world [14]. Grieving for such deaths is often more difficult due to some special features, including the sense of unreality about the bad death, exacerbation of feelings of guilt, need to blame others, frequent involvement of medical and legal authorities, sense of helplessness, obvious uneasiness attributable to a sudden increase in levels of adrenalin and other hormones, the 
unfinished business (including what they did not speak and the deceased related stuff they never managed to do, and an increased need for understanding and meaning [13], [15], [16]. Moreover, the "multiple losses" and "anticipatory grief" (i.e., grieving prior to the actual loss) may add to the complexity of grief [16], [17]. In this regard, multiple losses during the COVID-19 crisis could lead to a more severe bereavement that would leave the person on their own with a sense of repeated survivor. These survivors, assuming that the bigger society is not willing to know about their feelings, often doubt whether to express them [16], [18]. Furthermore, the spread of COVID-19 and the enforcement of social isolation programs, such as physical distancing, quarantine, selfisolation, and limiting or banning the physical presence of visitors in hospitals, have affected the possibility of PCBD occurrence [12], [13], [19]. Although all of the survivors are not at risk of $\mathrm{PCBD}$, it is incumbent on the therapist to specify how the current pandemic could cause PCBD after the death of a significant person [12].

\section{Materials and Methods}

\section{Search strategy}

Based on the search terms (i.e., bereavement, COVID-19, pandemics, and Worden's task-based model), related English papers published from 2000 to 2020 were searched in the EMBASE, PubMed, Web of Science, Scopus, Cochrane Library, and Google Scholar databases. Fundamental studies on PCBD during the COVID-19 crisis were examined, and the entire relevant literature was included. Quality appraisal assessed if the material exhibited an almost correct and reasonable argument for the presented themes. Eventually, the narrative technique was applied so that the material synthesis included creating a compelling and cohesive story. This depends on MacLure's [20] description of how a researcher engages with the material, that is, reading, writing, thinking, interpreting, arguing, and justifying. We used these data attempting to discuss critical topics in this realm, such as (1) diagnosing PCBD; (2) Worden's task-based model; (3) tasks of mourning; (4) mediators of mourning; (5) grief counseling versus grief therapy; and (6) pharmacotherapy.

\section{Results}

\section{Diagnosing PCBD}

Worden [21] provided four definitions for PCBD, or as he calls it "complicated mourning:"
(1) Chronic grief reaction (a reaction that drags on for a long time and would not yield a satisfactory result); (2) delayed grief reactions (when emotional reactions do not fit the loss, and the experience of grief symptoms for a subsequent loss would be intensified in the future); (3) exaggerated grief reactions (feeling overwhelmed or resorting to maladaptive behaviors following the loss, while the person is aware of the association of these symptoms with the grief); and (4) masked grief reactions (where the patients experience specific symptoms and behaviors but they are not aware of their association with the loss).

During the COVID-19 pandemic, multiple losses could delay mourning attributable to the weight and burden of bereavement overload [12], [22]. Such delayed reactions could occur not only following a subsequent loss but also by encountering other survivors or watching a movie/TV show/other media events about loss [23]. This process is consistent with Bowlby's view [23], which states that "earlier attachment figure" could revive the pain of the earlier loss as though it is being felt for the $1^{\text {st }}$ time.

However, in 2013, the American Psychiatric Association made five major alternations in DSM-5 that affected the definitions of grief, bereavement, and PCBD [9]. First, the simultaneous diagnosis of PTSD in the two $1^{\text {st }}$ months after the loss became possible. Second, the grief as an exclusive criterion was removed from the diagnostic category of adjustment disorders. Third, the separation anxiety disorder term was permitted to be applied to adults as well. In the fourth alternation, the diagnosis of PTSD was maintained as a manifestation of PCBD after the observation or awareness of a traumatic event (i.e., a sudden death). In the last alternation, the suggestive criterion of PCBD, that was applied to refer to the more than 1 year lasing mourning, was included in DSM-5 [9], [24], [25]. Although this clinical condition has not been officially confirmed by DSM-5 as a disorder, it might pave the way for the provision of a higher research budget as well as the coverage of health-care insurance [25].

Lazare [26] introduced an excellent taxonomy of clues to identify an unresolved grief reaction that can help diagnose PCBD during the COVID-19 pandemic (Table 1). Although these clues are not sufficient for a diagnostic conclusion, in case, each one of them is identified in a patient, the therapist should consider the possibility of the PCBD [25]. However, diagnostic decisions about bereavement should be conservative during the COVID-19 pandemic to prevent iatrogenic complications attributed to professional interventions (as well as consequential side effects) and interference in a normal human process [27].

\section{Worden's task-based model}

The very first grief theories became disfavored due to their extreme rigidity. However, new models 
Table 1: Diagnostic clues of persistent complex bereavement disorder [26]

Clue 1. Inability to talk about the deceased without experiencing an intense and fresh grief

Clue 2. Intense grief reaction following some relatively minor loss events

Clue 3 . Observing themes of loss during a clinical interview

Clue 4. Unwillingness to move the material possessions belonging to the deceased

Clue 5. Suffering the physical symptoms similar to those experienced by the deceased before his/her death

Clue 6. Creating radical changes in lifestyle by avoiding friends, family members, or activities associated with the deceased

Clue 7. A long history of subclinical depression that could be identified as persistent guilt, lowered self-esteem, and false euphoric feeling

Clue 8. A compulsion to imitate the deceased, which is caused by one's need to make up for the loss by feeling sympathy with the deceased

Clue 9. The existence of self-destructive impulses

Clue 10. Unaccountable sadness occurring at a certain time each year

Clue 11. A phobia about death caused by a specific illness got by the deceased

Clue 12. Avoid paying the gravesite a visit or taking part in death-associated activities or rituals

manage to identify specific relations and patterns in the idiosyncratic and complicated grief experience. One of the most applicable and inclusive grief theories is the task-based model, established by Worden [25]. The task-based model provides both clients and counselors with frameworks for guiding interventions and improves clients' self-efficacy and self-awareness. Worden [25] recognized grieving as an active process that engages the following four tasks: (1) Accepting the reality of loss; (2) processing the pain of grief; (3) adapting to a world without the deceased (involving internal, external, and spiritual adjustments); and (4) finding a longlasting connection with the deceased while starting a new life. Furthermore, Worden proposed seven mourning mediators critical to appreciate the client's experience. These mediators are as follows: (1) The character of the deceased; (2) the attachment of the bereaved to the deceased; (3) how the person died; (4) historical antecedents; (5) personality variables; (6) social mediators; and (7) concurrent stressors. Their assessment casts light on the protective factors introduced by the literature. They also create a required context to understand the grief experience's idiosyncratic nature. Further, some other issues need to be considered, such as the strength and style of the bereaved's attachment to the deceased, as well as the level of ambivalence and conflict with the deceased. Death-related factors, namely, degrees of violence or trauma, physical proximity, or death without body recovery, can have significant impacts on the bereaved [25]. In what follows, the Worden's model is detailed.

\section{Tasks of mourning}

Grief is defined as a cognitive process that requires facing and rebuilding views about the deceased, grief experience, and the changing world, wherein the survivor has to live now. This process, called grief work, comprises basic tasks that the survivor should accomplish to adapt to the loss (Table 2) [23], [25], [28], [29], [30], [31]. However, it is notable that these tasks are not similarly challenged in any death loss [32]. Certain features need to be taken into account as to the survivors of patients infected by COVID-19, who suffer from PCBD [12], [22]. Usually, unexpected death makes survivors have unreal feelings about the loss, which may last a long time. In such conditions, numbness, walking around in a daze, and experiencing nightmares and intrusive images are not uncommon [25]. Another special feature of survivors with PCBD is an increased need for understanding, which is typically accompanied by blame [25]. In fact, the first question that arises in the minds of COVID-19 survivors after an unexpected loss is "why this happened?" [12]. In such cases, there would be a strong need to find meaning, which should be seriously incorporated in the third mourning task [25].

Table 2: Tasks of mourning [23], [25], [28], [29], [30], [31]

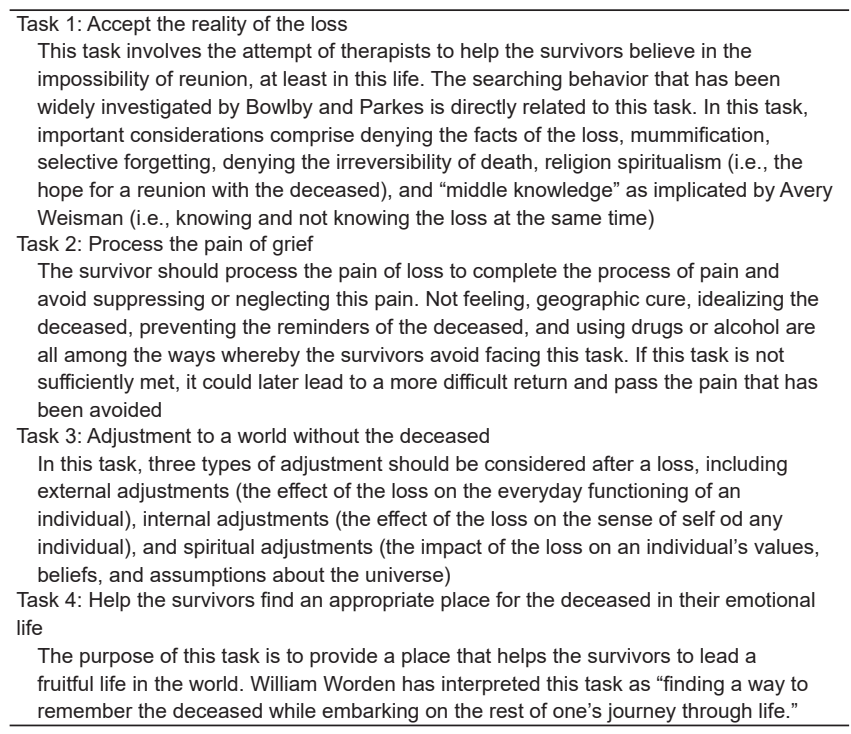

\section{Mediators of mourning}

Among many people experiencing an unexpected loss, there is a broad spectrum of symptoms involved in four general categories, including feelings, physical sensations, cognitions, and behaviors (Table 3) [3], [25]. Although it is incumbent on a therapist to know about this process, regardless of their viewpoint on it (such as stages, phases, or

Table 3: Symptoms of grief under four general categories [3], [25]

\begin{tabular}{ll}
\hline Feelings & $\begin{array}{l}\text { Anger, sadness, blame, anxiety, guilt and self-reproach, loneliness, } \\
\text { helplessness, fatigue, shock, emancipation, yearning, relief, numbness }\end{array}$ \\
\hline $\begin{array}{l}\text { Physical } \\
\text { sensations }\end{array}$ & $\begin{array}{l}\text { Hollowness in the stomach, tightness in the chest, tightness in the throat, } \\
\text { oversensitivity to noise, depersonalization, breathlessness, muscle } \\
\text { weakness, loss of energy, dry mouth }\end{array}$ \\
$\begin{array}{l}\text { Cognitions } \\
\text { Behaviors }\end{array}$ & $\begin{array}{l}\text { Confusion, disbelief, preoccupation, sense of presence, hallucinations } \\
\text { Sleep disturbances, eating disturbances, distracted and absentminded } \\
\text { behavior, dreams of the deceased, social withdrawal, sighing, avoiding } \\
\text { reminders of the deceased, restless hyperactivity, crying, visiting places or } \\
\text { carrying objects that remind the survivor of the deceased, treasuring the } \\
\text { objects belonging to the deceased }\end{array}$ \\
\hline
\end{tabular}


tasks), it is not adequate for effective grief counseling [25]. The grief varies among people according to its intensity and duration [33]. Among most people with PCBD in the time of the COVID-19 pandemic, for example, feelings of guilt, anger, helplessness, shock, numbness, disbelief, sleep disturbances, and restless hyperactivity are more severe and require special attention [16]. Therefore, it is essential to perceive the way of moderating these tasks through different factors to realize why people manage tasks of mourning differently, which is more significant when facing PCBD [12], [25].

As already stated, Worden [25] introduced seven key mourning mediators that influence the tasks of mourning. The kinship relationship with the deceased, as the first mediator, plays a prominent role in the response of these people to the loss. For instance, parents (especially mothers), widows, and the sisters of the deceased are more affected than adult children, widowers, and brothers [25]. The second mediator is the nature of the survivor's attachment to the deceased [25]. In this regard, the intensity of love for the deceased, the degree of the effectiveness of the presence of the deceased in the survivor's sense of well-being, ambivalence about the deceased, conflict with the deceased, and dependent relationships (like pre-loss marital dependence) could affect the reaction to grief [34], [35]. The third mediator is how the person died [17], [25], [36]. In COVID-19 crisis, the remoteness of the deceased at the moment of death, suddenness or unexpectedness of the death, and multiple losses could alter the process of grief [12]. The forth mediator is the historical antecedents, including the quality of the survivor's reaction to the prior losses, that is, whether he/she has mourned adequately and properly or has added the previous unresolved grief to the new loss [25]. The fifth mediator is personality variables [25]. The previous studies have demonstrated that grief reaction intensifies for the cases of preexisting mood and anxiety disorders, preexisting trauma (particularly childhood trauma), maladaptive coping styles, insecure attachment styles, rumination, and negative cognitive styles [37], [38]. The sixth mediator involves social variables [25]. Since mourning is a social phenomenon, the degree of perceived emotional and social support from family or others has a significant role in the mourning process, which has been highly affected by the COVID-19 pandemic [19]. Fear of contagion, stigma, and subsequent lack of social support are some of the challenges faced by therapists during the COVID-19 pandemic [12]. The last mediator is the concurrent losses and stresses [25]. It includes issues such as complicated economic problems (as a result of business restrictions during quarantine or loss of family head due to COVID-19), substance use, and inability to follow usual cultural practices of death and mourning [12], [13], [19]. Furthermore, these mediators have been classified into three main categories, namely, loss-related factors (mediators 1, 2, and 3), pre-loss risk factors (mediators 4 and 5), and periloss factors (mediator 7) [39].

According to Wortman and Silver's view [40], the distress levels of survivors are conspicuously affected by various mediators. Accordingly, therapists should seriously consider these mediators during the grief process, grief counseling, and grief therapy.

\section{Grief counseling versus grief therapy}

The occurrence of a wide range of grief reactions following a loss is a normal experience [41]. Some of the people, including individuals bereaved by COVID-19, might experience high levels of distress that leads them to seek counseling [12]. In such cases, grief counseling usually could help people adapt to the loss more efficiently [13]. In this regard, there are particular purposes based on the four mourning tasks, including (1) elevating the loss realism, (2) helping the survivors manage both behavioral and emotional pains, (3) providing the survivors with the ability to handle different impediments to readjustment (external, internal, and spiritual) after the loss, and (4) helping the survivors establish an approach to remembering and/or maintaining an emotional connection with the deceased while moving forward to reinvest in life [25]

A recent meta-analysis has shown that the preventive grief counseling (unlike treatment interventions) is not effective and could even be harmful [42]. However, in some cases, it is better to begin grief counseling as soon as possible but not in the first $24 \mathrm{~h}$ after the loss, unless the survivor and the therapist have been pre-connected [25]. This counseling process could be performed in a professional setting, informal setting (home environment), or through telephone contacts [12]. However, Parkes and Prigerson [43] stated that counseling processes in professional settings and through telephone contacts are the most and the least effective approaches, respectively. The grief counseling principles and procedures are illustrated in Figure 1 using Worden's task-based model [25]. Notice that grief counseling needs to follow a theoretical insight into human behavior and personality, not only according to mere settings of techniques [25]. In this regard, some techniques such as evocative language (using tough words to evocate the survivor's feelings like using the term "your son died" instead of "you lost your son"), use of symbols (using pictures or the belongings of the deceased), writing (writing a letter to the deceased and expressing the feelings and thoughts by the survivor), drawing (painting pictures reflecting the sentiments of an individual as well as what he/she experienced with the deceased), role-playing (helping the survivor to role-play various situations he/she fears), cognitive restructuring (particularly concerning covert thoughts and self-talk), memory books (creating a memory book for the deceased), directed imagery (helping the survivor visualize the deceased in an empty chair with closed eyes; then provoking the survivor to talk about what he/she needs to 


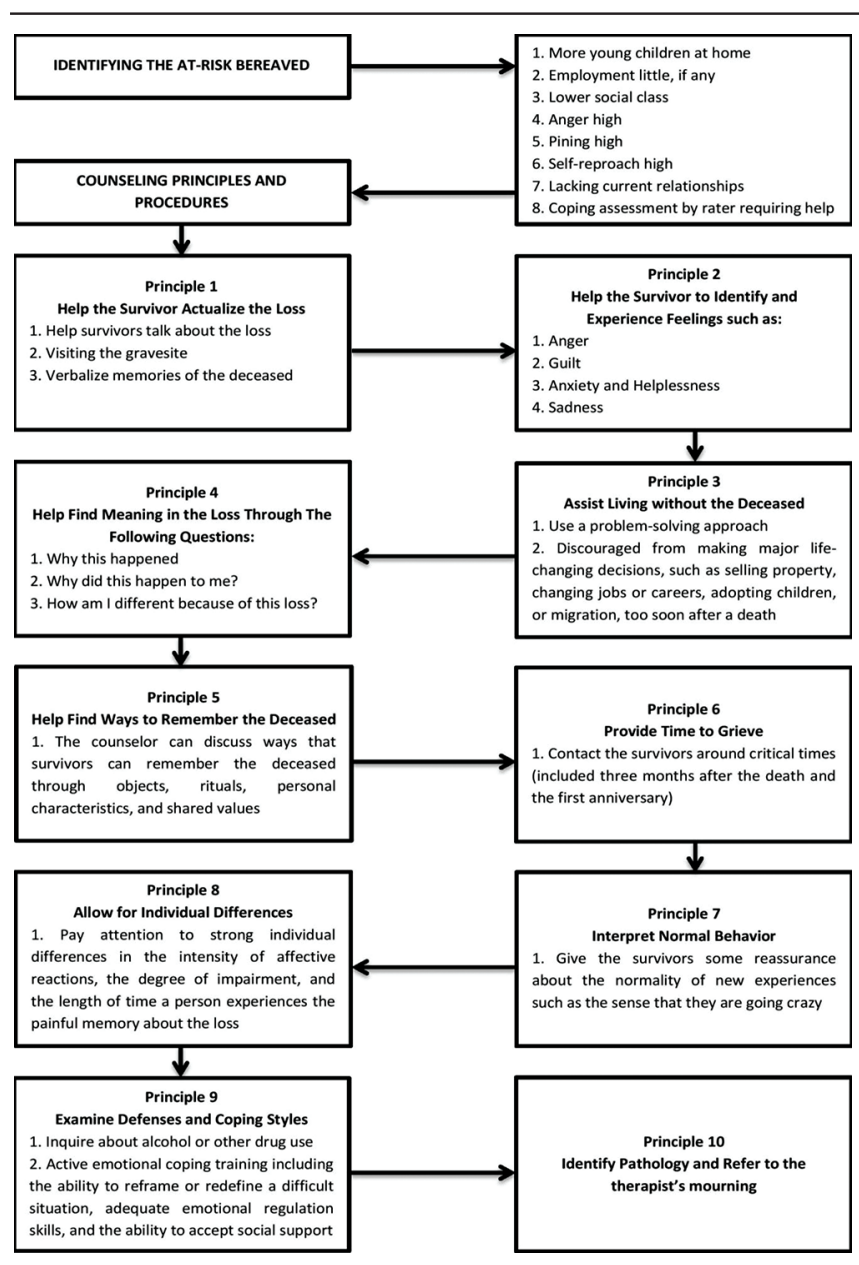

Figure 1: The stages of grief counseling during coronavirus disease-19 pandemic [25]

say to the deceased), and metaphors (a more acceptable symbolic representation of grief such as phantom pain and amputation related to the former image of loss) could provide an efficient grief counseling [25], [44], [45]. However, the aim of grief therapy is different from that of grief counseling to some extent [25]. Grief counseling aims to facilitate the grief tasks concerning the recent bereavement so that the survivor better adapts to the loss, whereas grief therapy aims at identifying and resolving the separation conflicts [25]. These conflicts prevent the completion of mourning tasks for those people suffering from PCBD [25]. Resolving these conflicts requires the experience of thoughts and feelings avoided by the patient. On this subject, the therapist would provide the patient with the opportunity to mourn through giving the social support required for a successful grief process, that is, an opportunity that might not be accessible at the moment of the death, which implicates a suitable therapeutic band [25]. One way to bolster this band is recognizing the difficulties that people might experience when dealing with a long-lasting intense grief. As the conflicts concerning the deceased become a more fundamental issue, the resistance to discovering painful feelings and thoughts increases. Hence, in any therapy, the resistances are always observed carefully and addressed as a component of the therapy process [25].
Grief therapy is mostly performed in a professional setting lasting from 2 to 20 sessions (depending on the types of treatment interventions) [46]. The therapeutic procedures for grief are briefly illustrated in Figure 2 using Worden's task-based model [25].

\section{Pharmacotherapy}

Although the psychological insight into the bereavement has been enhanced, there is still not an appropriate basis for biological interventions, except in cases with a serious psychiatric disorder such as major depressive disorder, post-traumatic stress disorder, and psychotic disorders [25]. Despite different viewpoints regarding the management of PCBD, there is an agreement on the treatment of anxiety and insomnia (not depressive symptoms) with low doses of medications [47], [48]. Prescribing antidepressants for people suffering from acute grief reactions due to the COVID-19 pandemic are not common for two reasons. First, these medications would work in long term and could hardly ever sedate acute grief reaction symptoms, aside from major depressive episodes [25]. Second, drug interactions have raised concerns among COVID-19 survivors [49]. In this respect, duloxetine, fluvoxamine, fluoxetine, phenelzine, sertraline, and vortioxetine are the only antidepressants that have the least interaction with the therapeutic regimens used in COVID-19 infection [50], [51].

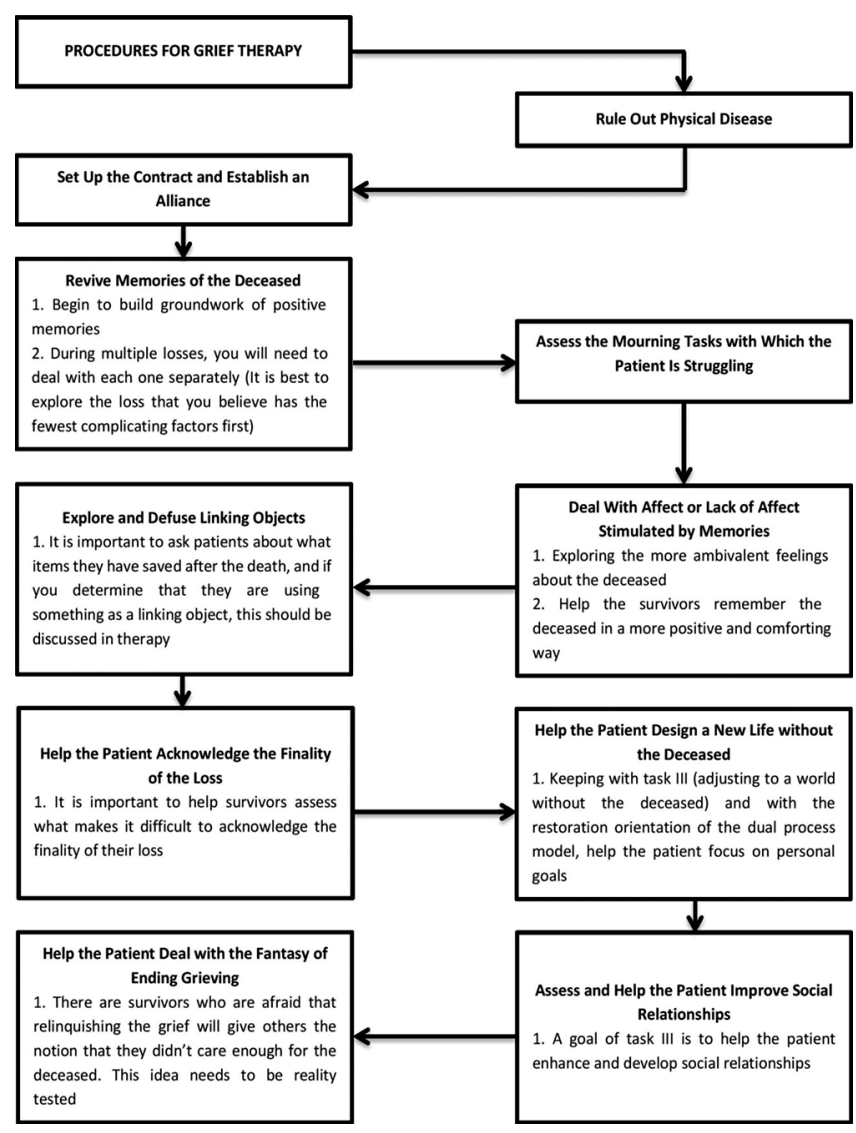

Figure 2: The stages of grief therapy during coronavirus disease-19 pandemic [25] 


\section{Conclusions}

The COVID-19 crisis will proceed with influencing more people. Loss and grief, as the most encompassing themes, interweaves many facets of people's life in different context. Thus, it is necessary to improve accessibility to evidence-based interventions, in both face-to-face and online formats, during the COVID-19 crisis [52], [53], [54]. It seems that Worden's task-based model may be effective in reducing the symptoms of PCBD. However, further investigations in this field need to be carried out through longitudinal empirical study.

\section{Authors' Contributions}

Mohsen Khosravi designed the study, collected the data, and drafted the manuscript. Furthermore, he read, revised, and approved the final manuscript.

\section{References}

1. Kaplow JB, Saunders J, Angold A, Costello EJ. Psychiatric symptoms in bereaved versus nonbereaved youth and young adults: A longitudinal epidemiological study. J Am Acad Child Adolesc Psychiatry. 2010;49(11):1145-54. https://doi. org/10.1097/00004583-201011000-00008 PMid:20970702

2. Boelen PA, Smid GE. Disturbed grief: Prolonged grief disorder and persistent complex bereavement disorder. BMJ. 2017;357:j2016. https://doi.org/10.1136/bmj.j2016 PMid:28522468

3. Zisook S, Shear K. Grief and bereavement: What psychiatrists need to know. World Psychiatry. 2009;8(2):67-74. https://doi. org/10.1002/j.2051-5545.2009.tb00217.x PMid:19516922

4. Bonanno GA, Malgaroli M. Trajectories of grief: Comparing symptoms from the DSM-5 and ICD-11 diagnoses. Depress Anxiety. 2020;37(1):17-25. https://doi.org/10.1002/da.22902 PMid:31012187

5. Lenferink LI, Nickerson A, de Keijser J, Smid GE, Boelen PA. Trajectories of grief, depression, and posttraumatic stress in disaster-bereaved people. Depress Anxiety. 2020;37(1):35-44. https://doi.org/10.1002/da.22850

PMid:30339302

6. Nielsen MK, Carlsen AH, Neergaard MA, Bidstrup PE, Guldin MB. Looking beyond the mean in grief trajectories: A prospective, population-based cohort study. Soc Sci Med. 2019;232:460-9. https://doi.org/10.1016/j. socscimed.2018.10.007 PMid:31230666

7. Freud S. Mourning and melancholia. In: Strachey J, editor.
Standard Edition of the Complete Psychological Works of Sigmund Freud. London, England: Hogarth Press; 1917/1957. p. 251-268

8. Kübler-Ross E. On Death and Dying. New York: Macmillan; 1969.

9. American Psychiatric Association. Diagnostic and Statistical Manual of Mental Disorders. $5^{\text {th }}$ ed. Arlington, VA: American Psychiatric Publishing; 2013.

10. Simon NM, Shear KM, Thompson EH, Zalta AK, Perlman C Reynolds CF, et al. The prevalence and correlates of psychiatric comorbidity in individuals with complicated grief. Compr Psychiatry. 2007;48(5):395-9. https://doi.org/10.1016/j. comppsych.2007.05.002

PMid: 17707245

11. Lichtenthal WG, Roberts KE, Prigerson HG. Bereavement care in the wake of COVID-19: Offering condolences and referrals. Ann Intern Med. 2020;173(10):833-5. https://doi.org/10.7326/ m20-2526 PMid:32574071

12. Wallace CL, Wladkowski SP, Gibson A, White P. Grief during the COVID-19 pandemic: Considerations for palliative care providers. J Pain Symptom Manage. 2020;60(1):e70-6. https:// doi.org/10.1016/j.jpainsymman.2020.04.012

PMid:32298748

13. Zhai $Y$, Du X. Loss and grief amidst COVID-19: A path to adaptation and resilience. Brain Behav Immun. 2020;87:80-1. https://doi.org/10.1016/j.bbi.2020.04.053 PMid:32335197

14. Rajgor DD, Lee MH, Archuleta S, Bagdasarian N, Quek SC The many estimates of the COVID-19 case fatality rate. Lancet Infect Dis. 2020;20(7):776-7. https://doi.org/10.1016/ s1473-3099(20)30244-9

PMid: 32224313

15. Carr D, Boerner K, Moorman S. Bereavement in the time of coronavirus: Unprecedented challenges demand novel interventions. J Aging Soc Policy. 2020;32(4-5):425-31. https:// doi.org/10.1080/08959420.2020.1764320 PMid:32419667

16. Eisma MC, Boelen PA, Lenferink LI. Prolonged grief disorder following the coronavirus (COVID-19) pandemic. Psychiatry Res. 2020;288:113031. https://doi.org/10.1016/j. psychres.2020.113031 PMid:32360895

17. Nielsen MK, Neergaard MA, Jensen AB, Bro F, Guldin MB. Do we need to change our understanding of anticipatory grief in caregivers? A systematic review of caregiver studies during end-of-life caregiving and bereavement. Clin Psychol Rev. 2016;44:75-93. https://doi.org/10.1016/j. cpr.2016.01.002 PMid:26796738

18. MercerDL, Evans JM. The impact of multiple losses on the grieving process: An exploratory study. J Loss Trauma. 2006;11(3):21927. https://doi.org/10.1080/15325020500494178

19. Farinha-Silva S, Reis-Pina P. COVID-19: From grief and mourning to prolonged grief disorder. Acta Med Port. 2020;33(10):709. https://doi.org/10.20344/amp.14701

20. MacLure M. Clarity bordering on stupidity: Where's the quality in systematic review? J Educ Pol. 2005;20(4):393-416. https://doi. org/10.1080/02680930500131801

21. Worden JW. Forms of complicated grief. In: Doka K, Tucci A, editors. When Grief is Complicated. Washington, DC: Hospice Foundation of America; 2017. p. 17-29.

22. Reja M, Naik J, Parikh P. COVID-19: Implications for advanced care planning and end-of-life care. West $J$ 
Emerg Med. 2020;21(5):1046-7. https://doi.org/10.5811/ westjem.2020.6.48049

PMid:32970552

23. Bowlby J. Attachment and Loss: Loss, Sadness, and Depression. Vol. 2. New York: Basic Books; 1980. https://doi.org/10.1093/ sw/26.4.355

24. Shear MK, Simon N, Wall M, Zisook S, Neimeyer R, Duan N, et al. Complicated grief and related bereavement issues for DSM-5. Depress Anxiety. 2011;28(2):103-17. https://doi. org/10.1002/da.20780

PMid:21284063

25. Worden JW. Grief Counseling and Grief Therapy: A Handbook for the Mental Health Practitioner. New York: Springer Publishing Company; 2018. https://doi. org/10.1891/9780826134752

26. Lazare A. Bereavement and unresolved grief. In: Lazare A, editor. Outpatient Psychiatry: Diagnosis and Treatment. $2^{\text {nd }}$ ed. Baltimore, MD: Williams \& Wilkins; 1989. p. 381-97.

27. Belitsky R, Jacobs S. Bereavement, attachment theory, and mental disorders. Psychiatr Ann. 1986;16(5):276-80. https://doi. org/10.3928/0048-5713-19860501-06

28. Attig T. How we Grieve: Relearning the World. New York: Oxford University Press; 2011.

29. Burke LA, Neimeyer RA. Complicated spiritual grief I: Relation to complicated grief symptomatology following violent death bereavement. Death Stud. 2014;38(1-5):259-67. https://doi.org/ $10.1080 / 07481187.2013 .829372$

PMid:24524589

30. Parkes CM, Prigerson HG. Bereavement: Studies of Grief in Adult Life. $4^{\text {th }}$ ed. New York: Routledge; 2013.

31. Weisman AD. On Dying and Denying. New York: Aronson; 1972.

32. Stroebe M. Coping with bereavement: A review of the grief work hypothesis. Omega. 1993;26(1):19-42. https://doi.org/10.2190/ tb6u-4qqc-hr3m-v9ft

33. Bonanno GA, Kaltman $\mathrm{S}$. The varieties of grief experience Clin Psychol Rev. 2001;21(5):705-34. https://doi.org/10.1016/ s0272-7358(00)00062-3

PMid: 11434227

34. Itzhar-Nabarro Z, Smoski MJ. A review of theoretical and empirical perspectives on marital satisfaction and bereavement outcomes: Implications for working with older adults. Clin Gerontol. 2012;35(3):257-69. https://doi.org/10.1080/07317115 2012.657604

35. Krupp G, Genovese F, Krupp T. To have and have not Multiple identifications in pathological bereavement. Am Acad Psychoanal. 1986;14(3):337-48. https://doi.org/10.1521/ jaap.1.1986.14.3.337

PMid:3744955

36. Gomes B, Calanzani N, Koffman J, Higginson IJ. Is dying in hospital better than home in incurable cancer and what factors influence this? A population-based study. BMC Med. 2015;13:235. https://doi.org/10.1186/s12916-015-0466-5 PMid:26449231

37. Eisma MC, Schut HA, Stroebe MS, Boelen PA, van den Bout J, Stroebe W. Adaptive and maladaptive rumination after loss: A three-wave longitudinal study. Br J Clin Psychol. 2015;54(2):16380. https://doi.org/10.1111/bjc.12067 PMid:25229192

38. Schenck LK, Eberle KM, Rings JA. Insecure attachment styles and complicated grief severity: Applying what we know to inform future directions. Omega. 2016;73(3):231-49. https://doi. org/10.1177/0030222815576124

39. Simon NM. Treating complicated grief. JAMA.
2013;310(4):416-23. https://doi.org/10.1001/jama.2013.8614 PMid:23917292

40. Wortman CB, Silver RC. The myths of coping with loss revisited. In: Stroebe MS, Hansson RO, Stroebe W, Schut $\mathrm{H}$, editors. Handbook of Bereavement Research: Consequences, Coping, and Care. Washington, DC: American Psychological Association; 2001. p. 405-29. https://doi. org/10.1037/10436-000

41. Schut H. Grief counselling efficacy: Have we learned enough? Bereavement Care. 2010;29(1):8-9. https://doi org/10.1080/02682620903560817

42. Wittouck C, Van Autreve S, De Jaegere E, Portzky G, van Heeringen $\mathrm{K}$. The prevention and treatment of complicated grief: A meta-analysis. Clin Psychol Rev. 2011;31(1):69-78. https://doi.org/10.1016/j.cpr.2010.09.005

PMid:21130937

43. Parkes $\mathrm{CM}$. Bereavement counselling: Does it work? $\mathrm{Br}$ Med J. 1980;281(6232):3-6. https://doi.org/10.1136/bmj.281.6232.3 PMid:7407489

44. Ihrmark C, Hansen EM, Eklund J, Stödberg R. You are weeping for that which has been your delight: To experience and recover from grief. Omega. 2011-2012;64(3):223-39. https://doi. org/10.2190/om.64.3.c

PMid:22455107

45. Lister S, Pushkar D, Connolly K. Current bereavement theory: Implications for art therapy practice. Arts Psychother. 2008;35(4):245-50. https://doi.org/10.1016/j. aip.2008.06.006

46. Johannsen M, Damholdt MF, Zachariae R, Lundorff M, FarverVestergaard I, O'Connor M. Psychological interventions for grief in adults: A systematic review and meta-analysis of randomized controlled trials. J Affect Disord. 2019;253:69-86. https://doi. org/10.1016/j.jad.2019.04.065 PMid:31029856

47. Bui E, Nadal-Vicens M, Simon NM. Pharmacological approaches to the treatment of complicated grief: Rationale and a brief review of the literature. Dialogues Clin Neurosci. 2012;14(2):149-57. https://doi.org/10.31887/dens.2012.14.2/ ebui

PMid:22754287

48. Simon NM, Shear MK, Fagiolini A, Frank E, Zalta A Thompson $\mathrm{EH}$, et al. Impact of concurrent naturalistic pharmacotherapy on psychotherapy of complicated grief. Psychiatry Res. 2008;159(1-2):31-6. https://doi.org/10.1016/j. psychres.2007.05.011

PMid: 18336918

49. Liverpool Drug Interactions Group. Interactions with Experimental COVID-19 Therapies. England: Liverpool Drug Interactions Group; 2020.

50. Anmella G, Arbelo N, Fico G, Murru A, Llach CD, Madero S, et al. COVID-19 inpatients with psychiatric disorders: Real-world clinical recommendations from an expert team in consultationliaison psychiatry. J Affect Disord. 2020;274:1062-7. https://doi. org/10.1016/j.jad.2020.05.149

PMid:32663933

51. Baradaran H, Gorgzadeh N, Seraj H, Asadi A Shamshirian D, Rezapour M. Drug-drug interaction between psychiatric medications and experimental treatments for coronavirus disease-19: A mini-review. Open Access Maced J Med Sci. 2020;8(1):216-28. https://doi.org/10.3889/ oamjms. 2020.5010

52. Sun $Y$, Bao $Y$, Lu L. Addressing mental health care for the bereaved during the COVID-19 pandemic. Psychiatry Clin Neurosci. 2020;74(7):406-7. https://doi.org/10.1111/ pcn. 13008 
PMid:32303110

53. Singer J, Spiegel JA, Papa A. Preloss grief in family members of COVID-19 patients: Recommendations for clinicians and researchers. Psychol Trauma. 2020;12(S1):S90-3. https://doi. org/10.1037/tra0000876
PMid:32478543

54. Bertuccio RF, Runion MC. Considering grief in mental health outcomes of COVID-19. Psychol Trauma. 2020;12(S1):S87-9. https://doi.org/10.1037/tra0000723

PMid:32478551 